\title{
Regional aortic compliance studied by magnetic resonance imaging: the effects of age, training, and coronary artery disease
}

\author{
R H MOHIADDIN, S R UNDERWOOD, H G BOGREN, D N FIRMIN, \\ R H KLIPSTEIN, R S O REES, D B LONGMORE \\ From the National Heart and Chest Hospitals, London
}

SUMMARY Arterial compliance was measured in 70 healthy volunteers, 13 athletes, and 17 patients with coronary artery disease. Magnetic resonance images were acquired at end diastole and end systole through the ascending aorta, the aortic arch, and the descending thoracic aorta. Regional compliance was derived from the change in luminal area in a slice of known thickness and from the pulse pressure. Total arterial compliance was also measured from the left ventricular stroke volume and the pulse pressure. In the volunteers, mean (SD) regional compliance $(\mu \mathrm{l} / \mathrm{mm} \mathrm{Hg})$ was greatest in the ascending aorta $(37(18)$ ), lower in the $\operatorname{arch}(31(15))$, and lowest in the descending aorta (18 (8)), and it decreased with age. Compliance in the athletes was significantly higher than in their age matched controls (41 (16) versus $22(11) \mu \mathrm{l} / \mathrm{mm} \mathrm{Hg}$ ). In the patients with coronary artery disease it was significantly lower (12 (4) $v 18(10)$ ) than in age matched controls. Total arterial compliance also fell with age in those with coronary artery disease although there was more variation.

The results suggest a possible role for compliance in the assessment of cardiovascular fitness and the detection of coronary artery disease.

A popular saying is that a man is as old as his arteries. The commonest arterial disease is "hardening of the arteries" or atherosclerosis which leads, among other things, to a loss of elasticity. Arterial elasticity is measured as compliance, which is the change in volume per unit change in pressure, and compliance measurements may be valuable for both detection and monitoring of disease.

Magnetic resonance imaging is a direct noninvasive way of studying regional aortic compliance and total arterial compliance. We used it to study changes in compliance with age and aortic compliance in athletes and in patients with coronary artery disease.

\section{Patients and methods}

We studied 70 healthy volunteers without symptoms of cardiovascular disease (mean age 38, range 16-83),

Requests for reprints to Dr R H Mohiaddin, Magnetic Resonance Unit, The National Heart and Chest Hospitals, 30 Britten Street, London SW3 6NN.

Accepted for publication 7 March 1989
13 athletes (mean age 43, range 29-56), and 17 patients with coronary artery disease without previous infarction (mean age 53, range 30-76). Three of the athletes were of international standard (one Olympic gold medal) and the others were club athletes. The average distance run daily was nine miles.

We used a Picker International Vista MR2055 machine operating at $0.5 \mathrm{~T}$ to acquire images at end diastole and end systole in three oblique planes perpendicular to the midpoints of the ascending aorta, the aortic arch, and the descending thoracic aorta (fig 1). A spin echo sequence (TE $40 \mathrm{~ms}$ ) was used with two averages of 128 phase encoding steps, a pixel size of $1.17 \mathrm{~mm} \times 1.17 \mathrm{~mm}$, and a slice thickness of $10 \mathrm{~mm}$. The end diastolic images were acquired $100 \mathrm{~ms}$ before the average $R R$ interval, and the end systolic images at the end of the $T$ wave of the electrocardiogram Acquisition time was three to four minutes per image depending upon heart rate.

The lumen of the aorta was outlined manually on the computer screen, and regional aortic compliance was calculated from the change in volume between diastole and systole. The pulse pressure was 


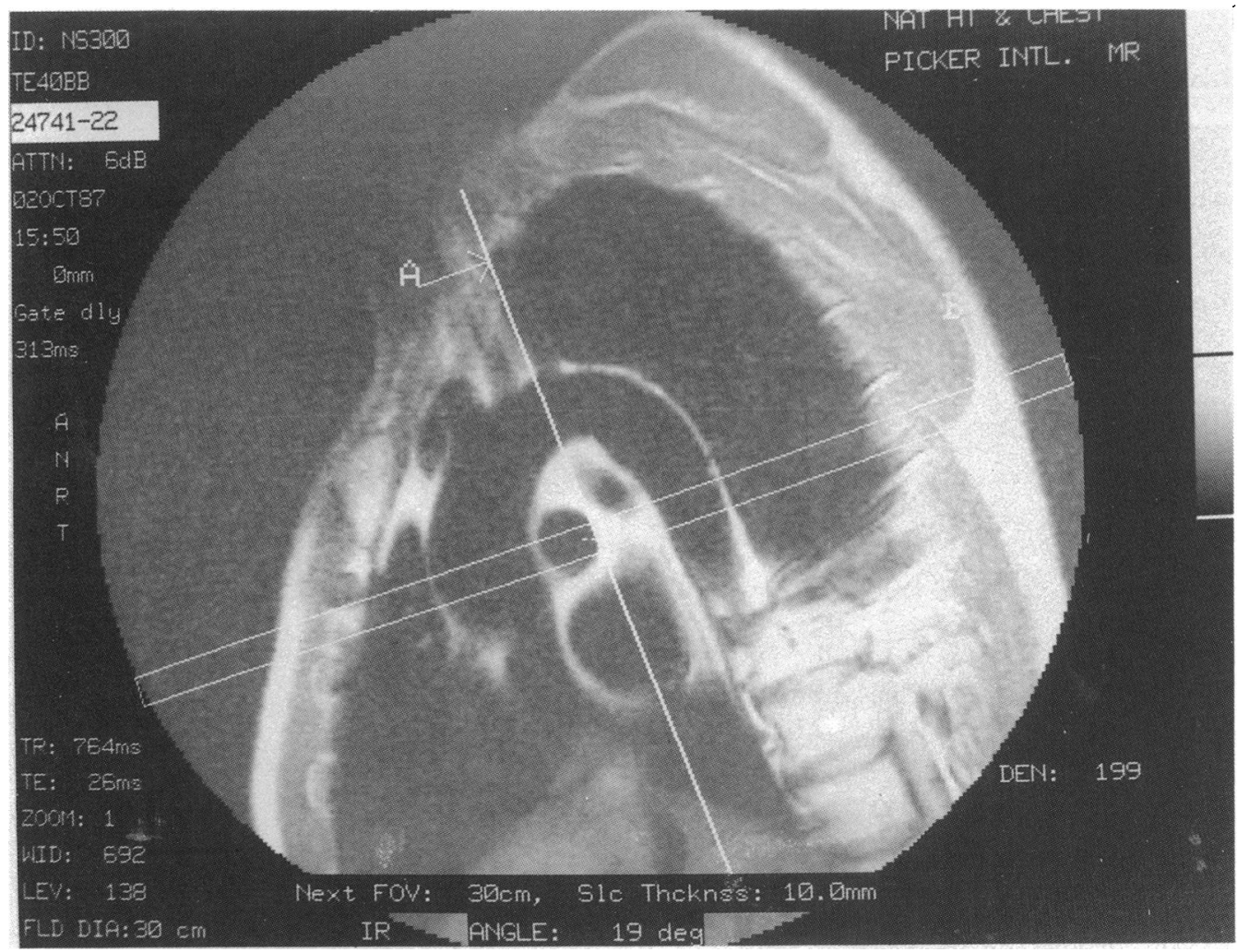

Fig 1 Oblique image of the ascending aorta, aortic arch, and descending thoracic aorta showed the sites at which compliance was measured.

measured with a conventional sphygmomanometer. Left ventricular end diastolic and end systolic volumes were calculated from biplane area-length measurements in the horizontal and vertical long axis planes, ${ }^{1}$ and total arterial compliance was derived from the left ventricular stroke volume and the pulse pressure.

We used the unpaired Student's $t$ test to test the differences between groups, and used a correction for multiple comparisons for comparisons between sites. ${ }^{2}$ Normal ranges for compliance were derived from the $95 \%$ confidence intervals of the linear regression lines in figs 3-5. Linear regression was performed after logarithmic transformation because the relation between compliance and age was curved.

\section{Results}

Figure 2 shows images at end diastole and end systole through the ascending and descending aorta in a volunteer aged 38 . The mean (SD) percentage change in ascending aortic area in volunteers aged less than 50 was $30(13) \%$, which was significantly greater than the known reproducibility of area measurements by this technique $(6 \%){ }^{3}$

Mean (SD) regional compliance measurements in the healthy volunteers (mean (SD) age 37) were (30.9 $(15.3)$ ) in the ascending aorta, $21.4(10.7)$ in the aortic arch, $17.8(8.3)$ in the descending aorta, and total arterial compliance was $1854(489)(\mu \mathrm{l} / \mathrm{mm} \mathrm{Hg})$. Mean compliance in the ascending aorta was higher than in the arch ( $p<0.01$ by the multiple comparison test) and in the descending aorta $(p<0.01)$. The

Table 1 Mean regional compliance (SD) in patients with coronary artery disease and athletes compared with age matched volunteers. The values are the means of each site in all the subjects in each group

\begin{tabular}{lll}
\hline & Age & Compliance \\
\hline Age matched volunteers & $47(11)$ & $17.6(10 \cdot 3)$ \\
$\begin{array}{l}\text { Patients with coronary artery } \\
\quad \text { disease }\end{array}$ & $53(11)$ & $11.6(4 \cdot 0)^{\star \star}$ \\
Age matched volunteers & $41(9)$ & $21.8(11 \cdot 2)$ \\
Athletes & $47(7)$ & $41.0(16 \cdot 2)^{\star \star \star}$ \\
\hline
\end{tabular}

$\star \star p<0.01, \star \star \star p<0.001$. 

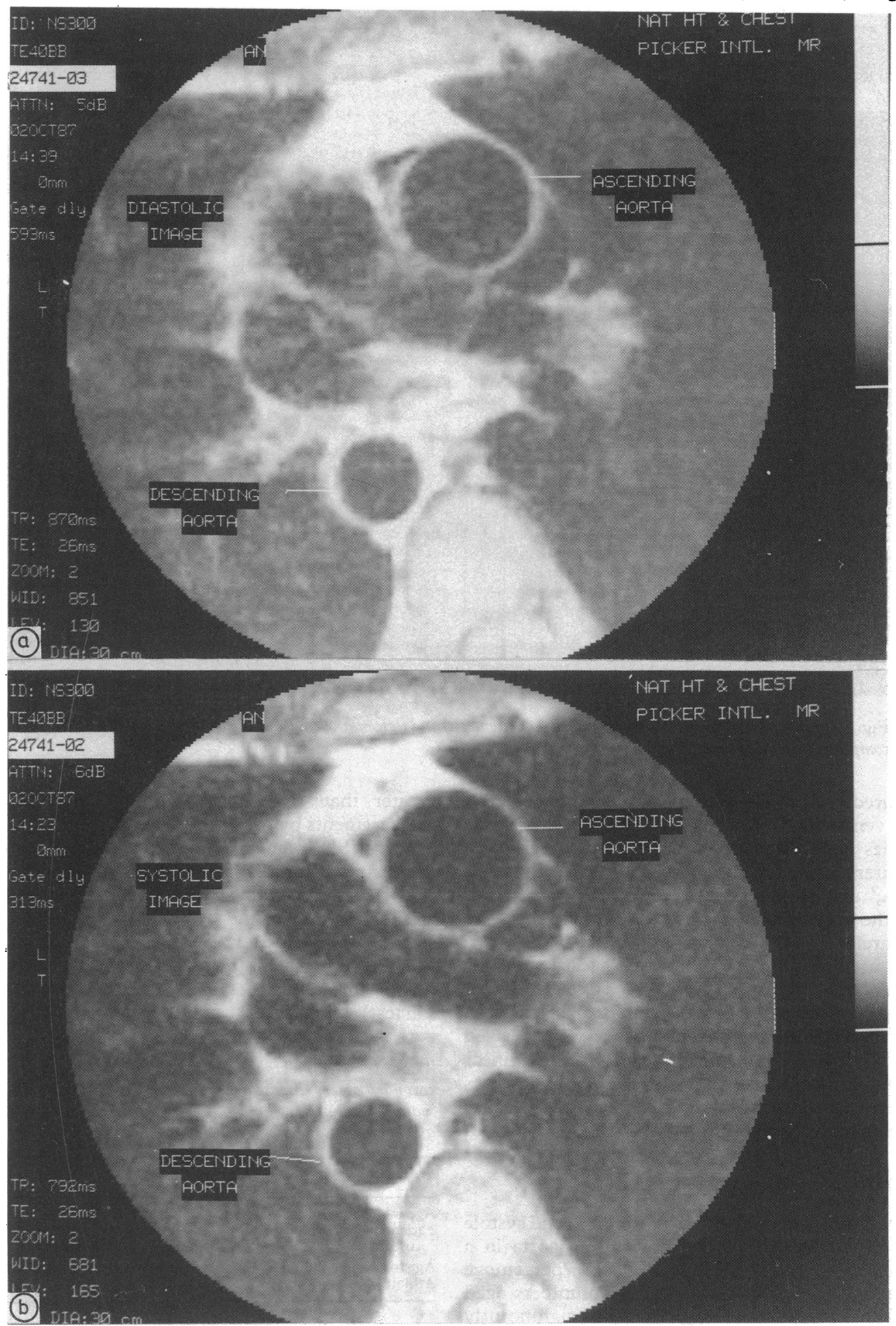

Fig 2 Diastolic ( $a$ ) and systolic images ( $b$ ) of the ascending and descending aorta showing the change in aortic area of a 38 year old normal volunteer. 


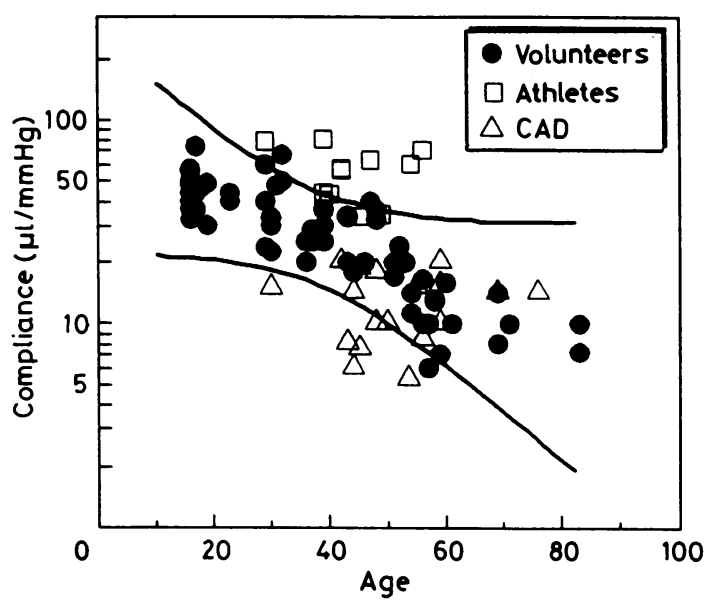

Fig 3 Compliance in the ascending aorta displayed on a logarithmic scale and plotted against age. The regression equation is $y=-0.01 x+1 \cdot 79$, and the $95 \%$ confidence intervals for the normal volunteers are shown $(r=-0.91$, $p<0.001, S E E=0.09$ ).

difference in compliance between the arch and the descending aorta was not significant $(p>0.05)$.

Mean compliance in the athletes and in the patients with coronary artery disease was compared with age matched volunteers. Compliance was significantly higher in the athletes and lower in the patients with coronary artery disease than in their age matched controls (table 1 ).

Figures 3-5 show the relation between compliance and age in all those studied. Compliance fell with age

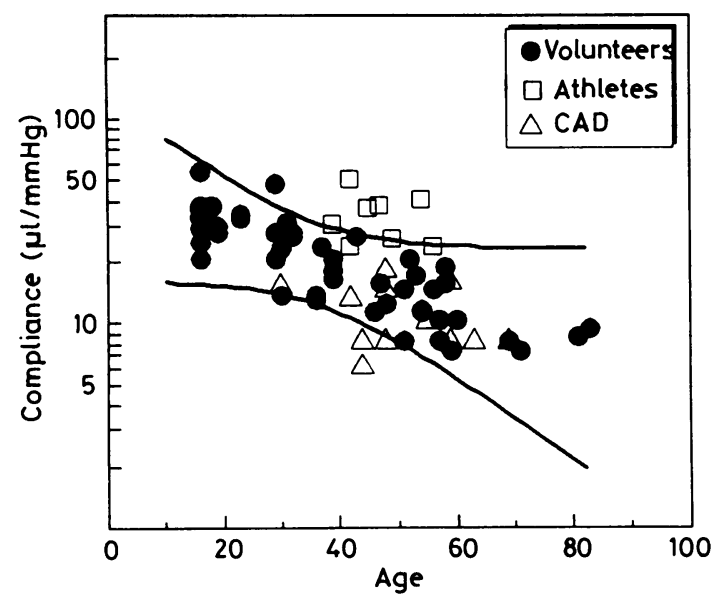

Fig 4 Compliance of the aortic arch displayed on a logarithmic scale and plotted against age. The regression equation is $y=-0.01 x+1.65$ and the $95 \%$ confidence intervals for the normal volunteers are shown $(r=-0.84$, $p<0.001, S E E=0.12$ ).

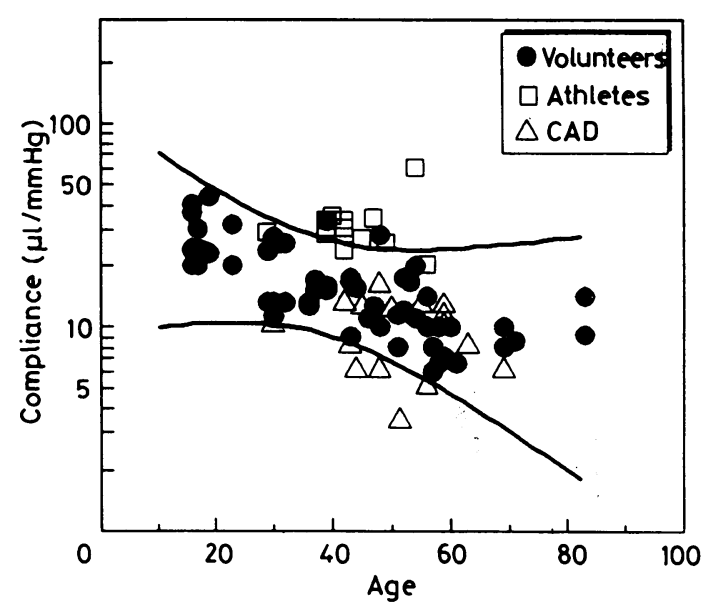

Fig 5 Compliance in the descending aorta displayed on a logarithmic scale and plotted against age. The regression is $y=-0.008 x+1.5$, and the $95 \%$ confidence intervals for the normal volunteers are shown $(r=-0.74, p<0.001$, $S E E=0.14$ ).

in the volunteers and after logarithmic transformation the fall seemed to be linear. The $95 \%$ confidence intervals of the linear regression equations were used to define a normal range. All but three athletes had compliance above the normal range at each site. Of the patients with coronary artery disease who were aged $<50$, most had abnormally low compliance in the ascending aorta, aortic arch, and descending aorta. Mean compliance in the patients with coronary artery disease was abnormally low, and inspection of the figures showed that the difference was most pronounced in patients aged $<50$. Compliance was high in the controls aged $>50$. Total arterial

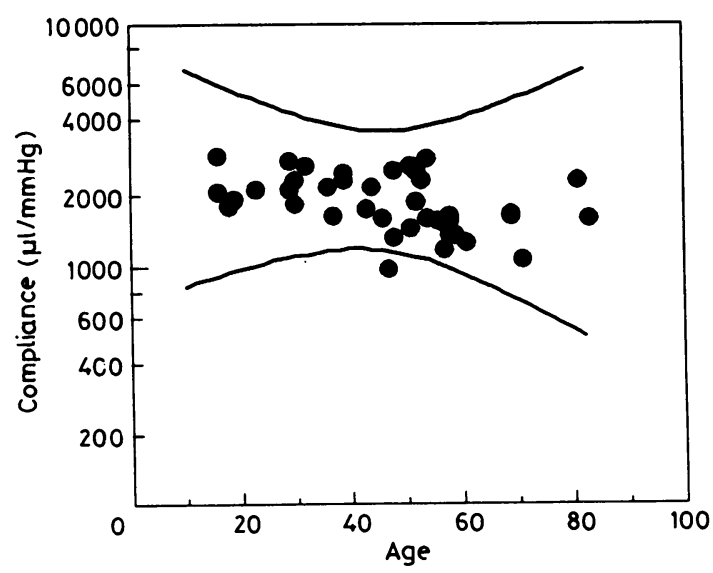

Fig 6 Total arterial compliance in the normal volunteers plotted against age. The regression equation is $y=-0.003$ $x+3.39, r=-0.42, p<0.02, S E E=0.11$. 


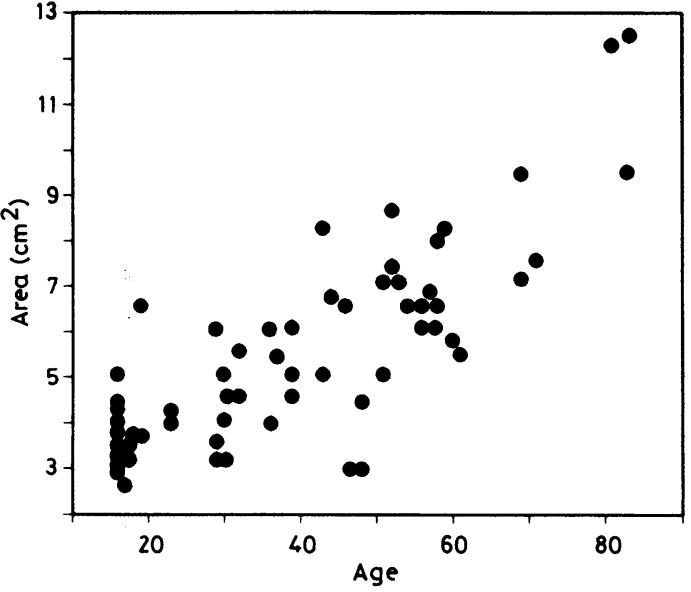

Fig 7 Correlation between area of the ascending aorta in diastole and age $(y=0.09 x+2 \cdot 1, r=0.77, S E E=1.4$ $\mathrm{cm}^{2}$ ).

compliance also decreased with age in the healthy volunteers, but there was a wide scatter of points (fig 6).

Figure 7 and table 2 show the relation between diastolic aortic area and age, and fig 8 shows the change in pulse pressure with age in the healthy volunteers. Aortic size and pulse pressure both increased with age, pulse pressure mainly because of an increase in systolic pressure.

\section{Discussion}

Previous workers have measured human arterial compliance from pressure-volume curves of post-

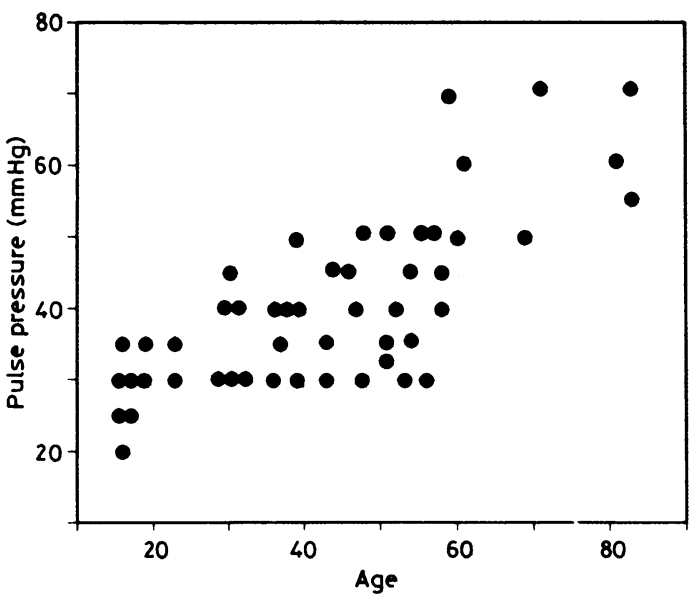

Fig 8 Correlation between pulse pressure in the normal volunteers and age $(y=0.5 x+0.5, r=0.80, S E E=7.2$ $\mathrm{mm} \mathbf{H g}$ ).
Table 2 Mean (SD) cross sectional area of ascending aorta in each decade in the healthy volunteers

\begin{tabular}{ll}
\hline Age (decades) & Diastolic aortic area $\left(\mathrm{cm}^{2}\right)$ \\
\hline $10-19$ & $3 \cdot 8(0 \cdot 9)$ \\
$20-29$ & $4 \cdot 3(1 \cdot 1)$ \\
$30-39$ & $4 \cdot 9(0 \cdot 8)$ \\
$40-49$ & $5 \cdot 3(2 \cdot 0)$ \\
$50-59$ & $6 \cdot 9(0 \cdot 9)$ \\
$60-69$ & $7 \cdot 0(1 \cdot 8)$ \\
$70-79$ & $8 \cdot 1(0 \cdot 6)$ \\
$80-89$ & $11 \cdot 0(2.9)$ \\
\hline
\end{tabular}

mortem arteries. ${ }^{4}$ Arterial compliance has also been estimated in vivo by indirect and invasive techniques, including pulse wave velocity measurements in animals and in humans, ${ }^{5-7}$ the pressure-radius relation by the Peterson transformer coil in animals, ${ }^{8}$ $x$ ray contrast angiography in humans, ${ }^{9}$ and pulsed ultrasound aortography. ${ }^{10}$ The compliance of the whole arterial system has previously been calculated from the left ventricular stroke volume divided by pulse pressure. ${ }^{11}$ We showed that both regional aortic compliance and total arterial compliance can be measured in vivo by magnetic resonance, which is simpler and more accurate than other methods. ${ }^{12}$

We showed that regional aortic compliance in healthy volunteers falls with age and is highest in the ascending aorta; this accords with studies that showed that this part of the aorta had the greatest elasticity. ${ }^{13} \mathrm{~W}$ ith advancing age, there is disruption of the elastic component of the vessel wall, fibrosis and increase in collagen at the expense of smooth muscle cells, cystic medial necrosis (pooling of mucoid material), and medionecrosis (areas with loss of nuclei) ${ }^{14-16}$ The fall in compliance with age may also be related to a deficiency of endothelium derived relaxing factor ${ }^{17}$ or to the disappearance of peripheral $\beta$ adrenergic receptors. ${ }^{18}$ The enlargement of diastolic aortic area with age is possibly caused by the structural changes and loss of elasticity in the vascular wall. A previous necropsy study on adult human aortas showed that the enlargement of aortic diameter with age was associated with loss of elasticity. ${ }^{19}$ Systolic blood pressure and pulse pressure increase with age. ${ }^{20} \mathrm{~A}$ fall in arterial compliance may be one factor causing systolic hypertension, ${ }^{21-23}$ although the structural changes seen in elderly patients with hypertension have also been reported in normotensive individuals of the same age $\mathrm{e}^{24}$ and to a lesser degree in younger subjects. ${ }^{25}$ Decreased compliance may also lead to the decreased baroreceptor sensitivity seen in elderly patients with hypertension..$^{26}$ The relation between blood pressure and compliance is complex, however, because hypertension can be a cause as well as a consequence of reduced compliance. ${ }^{28}$ 
We found high regional aortic compliance in trained athletes, and it seems likely that this is due to a direct effect of training upon the arterial system, rather than its effects upon the heart. Although the bradycardia and increased stroke volume of training ${ }^{29}$ will affect mean aortic diameter and hence compliance, there are also large changes in peripheral resistance that should have a greater effect. The reduction in resistance allows the athlete to generate a maximum cardiac output of up to $40 \mathrm{l} / \mathrm{min}$ compared with a maximum of $20 \mathrm{l} / \mathrm{min}$ in normal individuals without increasing blood pressure to unacceptable values. ${ }^{3031}$ These large changes in peripheral resistance may well be accompanied by structural changes in the aorta leading to increased compliance.

Because compliance is a determinant of left ventricular afterload it is important in patients with coronary artery disease. ${ }^{32}$ The combination of elastic arteries and resistant arterioles constitutes a hydraulic filter enabling the intermittent cardiac output to be converted to a steady capillary flow. Part of the energy of left ventricular contraction produces forward flow during systole, but the remainder is stored as potential energy in the distended arteries. During diastole, elastic recoil converts this potential energy again into forward flow. A fall in aortic compliance, therefore, increases the impedance to ventricular ejection and decreases capillary blood flow. ${ }^{334}$ Aortic compliance measured by aortography was reduced in patients with coronary artery disease ${ }^{35}$ and we have now shown similar changes noninvasively. Although it is possible that this is due to the mechanical effects of atheroma, it is more likely to reflect the generalised structural changes that occur in association with atheroma and that are similar to those of aging. ${ }^{36} 37$

Magnetic resonance imaging is a simple noninvasive method of measuring both regional aortic compliance and total arterial compliance. In healthy volunteers, the ascending aorta was the most compliant region and compliance fell more distally. Compliance also fell with age, although above the age of 50 the fall was less steep. Regional aortic compliance is higher than normal in athletes, and lower than normal in patients with coronary artery disease. These changes are likely to be the result of structural changes in the aorta, but the importance of compliance measurements for the monitoring of cardiovascular fitness and for the detection of disease remains to be established.

We thank the Board of Governors of the National Heart and Chest Hospitals, the Coronary Artery Disease Research Association (CORDA), and Picker International Ltd, for financial support and Miss
Elizabeth Burman, Mr Karl Lotey, and Miss Marjorie Watson for their assistance.

\section{References}

1 Underwood SR, Gill CRW, Firmin DN, et al. Left ventricular volume measured rapidly by oblique magnetic resonance imaging. $\mathrm{Br}$ Heart $J$ 1988; 60:188-95.

2 Pocock SJ. Clinical trials, a practical approach. Chichester: John Wiley \& Sons, 1983:231-3.

3 Klipstein RH, Underwood SR, Firmin DN, et al. Limits of intraobserver reproducibility of volume and ejection fraction measurement from magnetic resonance cardiac images [Abstract]. Berkeley: Society of Magnetic Resonance in Medicine, 1987;6:791.

4 Hallock P, Benson IC. Studies on the elastic properties of human isolated aorta. J Clin Invest 1937;15: 595-602.

5 Hallock P. Arterial elasticity in man in relation to age as evaluated by the pulse wave velocity method. Arch Intern Med 1934;54:770-98.

6 Bramwell JC, Hill AV, McSwiney BA. The velocity of the pulse wave in man in relation to age as measured by hot-wire sphygmograph. Heart 1923;10:233-55.

7 Messerli FH, Ventura H, Aristimuno GG, Suarez DH, Dreslinski GR, Frohlich ED. Arterial compliance in systolic hypertension. Clin Exp Hypertens 1982; [A] A4(7):1037-44.

8 Remington JW. Pressure-diameter relations of the in vivo aorta. Am J Physiol 1962;203:440-8.

9 Luchsinger PC, Sachs M, Patel D. Pressure-radius relationship in large blood vessels of man. Circ Res 1962;11:885-7.

10 Gosling R, King D, Newman D, Taylor G, Weindling $M$. Measurement of aortic elasticity and its relevance to atherogenesis. In: Roberts C, ed. Blood flow measurement. London: Sector Publishing, 1972:37-9.

11 Ferguson JJ, Randall OS. Hemodynamic correlates of arterial compliance. Cathet Cardiovasc Diagn 1986;12:376-80.

12 Longmore DB, Klipstein RH, Underwood SR, et al. Dimensional accuracy of magnetic resonance in studies of the heart. Lancet 1985;i:1360-2.

13 Azuma T, Hasegawa MA. Rheological approach to the architecture of the arterial walls. Jpn J Physiol 1971;21:27-47.

14 Schlatmann TJ, Becker AE. Histologic changes in the normal aging aorta: implication for dissecting aneurysms. Am J Cardiol 1977;39:13-20.

15 Banga I, Balo J. Elasticity of the vascular wall. 1 The elastic tensibility of the human carotid as a function of age and atherosclerosis. Acta Physiologica 1961;20:237-47.

16 Spina M, Garbin G. Age related chemical changes in human elastins from non-atherosclerotic areas of the thoracic aorta. Atherosclerosis 1976;24:267-79.

17 Griffith TM, Lewis MJ, Newby AC, Henderson AH. Endothelium derived relaxing factor. J Am Coll Cardiol 1988;12:797-806.

18 Schoken D, Roth GS. Reduced beta adrenergic 
receptor concentrations in aging in man. Nature 1977;267:856-8.

19 Wilens S. The postmortem elasticity of the adult human aorta. Its relation to age and to distribution of intimal atheroma. Am J Pathol 1937;14:811-34.

20 Hamilton M, Pickering G, Roberts F, Sowery G. The aetiology of essential hypertension. 1 The arterial pressure in the general population. Clin Sci 1954; 13:11-35.

21 Ferguson JJ, Julius S, Randall O. Stroke volume pulse pressure relationships in borderline hypertension: a possible indicator of decreased arterial compliance. J Hypertens 1984;2(suppl 3):397-9.

22 Randall O, van den Bos GC, Westerhof N. Systemic compliance: does it play a role in the genesis of essential hypertension? Cardiovasc Res 1984;18: 455-62.

23 Simon A, Levenson J. Overview on atherosclerotic systolic hypertension. Int J Cardiol 1987;16:1-18.

24 Simon AC, Safar ME, Levenson JA, Kheder AD, Levy BI. Systolic hypertension: hemodynamic mechanism and choice of antihypertensive treatment. Am J Cardiol 1979;44:505-11.

25 Lund-Johansen P. Hemodynamic changes in late hypertension. In: Onesti G, Kim KE, eds. Hypertension in the young and the old. New York: Grune and Stratton, 1981:239-49.

26 Randall O, Elser M, Culp B, Julius S, Zweifler A. Determinants of baroreflex sensitivity in man. $J$ Lab Clin Med 1978;91:514-9.

27 Simon AC, Safar ME, Weiss YA, London GM, Milliez PL. Baroreflex sensitivity and cardiopulmonary blood volume in normotensive and hypertensive patients. Br Heart J 1977;39:799-805.

28 Randall O, Esler M, Calfee R, Bulloch G, Maisel A, Culp B. Arterial compliance in hypertension. Aust NZ J Med 1976;6(supp 2):49-59.

29 Blomqvist GC. Cardiovascular adaptations to physical training. Annu Rev Physiol 1983;45:169-89.

30 Clausen JP. Circulatory adjustments to dynamic exercise and effect of physical training in normal subjects and in patients with coronary artery disease. Prog Cardiovasc Dis 1976;18:459-95.

31 Clausen JP. Effect of physical training on cardiovascular adjustments to exercise in man. Physiol Rev 1977;57:779-815.

32 Urschel CW, Covel JW, Sonnenblick EH, Ross J, Braunwald $E$. The effect of decreased aortic compliance on performance of the left ventricle. $\mathrm{Am} \mathrm{J}$ Physiol 1968;214:298-304.

33 Berne RM, Levy MN. Cardiovascular physiology. London: CV Mosby, 1981:94-7.

34 Wilcken DE, Charlier AA, Hoffman JI, Guz A. Effect of alterations in aortic impedance on the performance of the ventricles. Circ Res 1964;14:283-93.

35 Stefandis C, Wooley CF, Bush CA, Kolibash AJ, Boudoulas $\mathrm{H}$. Aortic distensibility abnormalities in coronary artery disease. Am J Cardiol 1987;59: $1300-4$.

36 Eggen DA, Solberg LA. Variation of atherosclerosis with age. Lab Invest 1968;18:571-9.

37 Farrar D, Green H, Wanger W, Bound GM. Reduction in pulse wave velocity and improvement of aortic distensibility accompanying regression of atherosclerosis in the rhesus monkey. Circ Res 1980;47: 425-32. 